\title{
Quality of Life in Early Breast Cancer Patients: A Prospective Observational Study Using the FACT-B Questionnaire
}

\author{
LUCIA ANNA URSINI ${ }^{1}$, MARIANNA NUZZO ${ }^{1}$, CONSUELO ROSA ${ }^{1,2}$, FIORELLA CRISTINA DI GUGLIELMO ${ }^{1}$, \\ MONICA DI TOMMASO ${ }^{1}$, MARIANNA TRIGNANI ${ }^{1}$, MARZIA BORGIA $^{1}$, \\ ALBINA ALLAJBEJ ${ }^{1}$, FABIOLA PATANI $^{1}$, CLELIA DI CARLO $^{1}$, ANNAMARIA PORRECA ${ }^{3}$, \\ MARTA DI NICOLA ${ }^{4}$, DOMENICO GENOVESI ${ }^{1,2}$ and LUCIANA CARAVATTA ${ }^{1}$ \\ ${ }^{1}$ Department of Radiation Oncology, SS. Annunziata Hospital, “G. D’Annunzio” University of Chieti, Chieti, Italy; \\ ${ }^{2}$ Department of Neuroscience, Imaging and Clinical Sciences, “G. D'Annunzio” University of Chieti, Chieti, Italy; \\ ${ }^{3}$ Department of Economics, "G. D'Annunzio" University of Chieti-Pescara, Pescara, Italy; \\ ${ }^{4}$ Laboratory of Biostatistics, Department of Medical, Oral and Biotechnological Sciences, \\ “G. D’Annunzio” University of Chieti, Chieti, Italy
}

\begin{abstract}
Background/Aim: Quality of life (QoL) in early breast cancer $(B C)$ treatment may be affected by acute and late toxicities. This study evaluated the impact of radiotherapy $(R T)$ schedules, treatment-related toxicities, hormone therapy (HT) and age on QoL. Patients and Methods: Ninety-five patients answered the FACT-B 4.0 questionnaire. Acute or late toxicities were recorded at each follow-up visit. Results: The median trend of the QoL subscales was stable during all questionnaires. HT negatively impacted on Functional Assessment of Cancer TherapyGeneral-Total, functional and emotional wellbeing. No difference was recorded between RT schedules and toxicity. No significant differences for age were detected in QoL. Conclusion: RT seems not to influence QoL of BC patients, in terms of fractionation regimen or RT-related side-effects. Moreover, women having systemic HT experienced a $Q o L$ worse than patients treated with RT only. Further and longterm protocols are needed to improve the validity of the tool.
\end{abstract}

Advances in diagnosis and treatment of breast cancer (BC) have led to an increase in cancer survival, resulting in quality of life (QoL) improvement. Breast conserving surgery followed by adjuvant radiation therapy (RT) is the current

This article is freely accessible online.

Correspondence to: Consuelo Rosa, MD, Department of Radiation Oncology, SS. Annunziata Hospital, "G. D'Annunzio" University of Chieti, Via Dei Vestini, 66100 Chieti, Italy. Tel: +39 0871358244, Fax:+390871357473, e-mail: c.rosa155@gmail.com

Key Words: Early breast cancer, hormone therapy, hypofractionation, quality of life, radiation therapy. standard treatment for early BC. Local and systemic treatments could cause skin dyschromia, lymphedema, fatigue, hot flashes, sexual dysfunction, and arthralgia with consequent changes in physical appearance and routine activities. These toxicities may persist for a long time after treatment with a subsequent decline in QoL (1). Studies have shown that in clinical trials QoL represents an important endpoint, whose assessment could contribute to improved treatment and patient's satisfaction (2-5). Under this scenario, the main aim of the study was to evaluate the impact of RT and hormone therapy (HT) on the QoL during the first 2 years after RT. Fractionation schedules (conventional vs. hypofractionation), radiation toxicities and age were also investigated. QoL was evaluated with Functional Assessment of Chronic Illness Therapy General Questionnaire and its Breast Cancer Supplement (FACT-B) questionnaire (https://www.facit.org), version 4.0 in Italian language. This tool is deemed as a quick and well validated multi-dimensional self-report questionnaire with subscales measuring physical, social, emotional, and functional wellbeing and contains additional concerns in breast cancer (6).

\section{Patients and Methods}

The study was designed as a prospective observational research project and was approved by the Ethics Committee of the "SS Annunziata" Hospital, "G. D'Annunzio" University, Chieti, Italy on $9^{\text {th }}$ May 2018. All patients were treated in our Radiotherapy Department and provided written informed consent. Medical records of enrolled patients were marked by a pink circle to streamline the identification process during treatment and follow-up.

Inclusion criteria were: female patients, age $\geq 18$ years, histologically proven breast cancer, ductal carcinoma in situ and invasive carcinoma stage I-II, breast conservative surgery and adjuvant radiotherapy. 
Exclusion criteria were: neoadjuvant or adjuvant chemotherapy, neoadjuvant hormone therapy, psychiatric disorder or addictions, loco-regional relapse, previous diagnosed cancer, active collagenopathies and distant metastasis.

QoL was evaluated with Functional Assessment of Chronic Illness Therapy General Questionnaire, including Breast Cancer Supplement (FACT-B) questionnaire (https://www.facit.org), version 4.0 in Italian language. It consists of a standardized approach to objectively evaluate and quantify the overall health status of patients employing a quick and well validated multi-dimensional self-report questionnaire with subscales measuring physical, social, emotional, and functional well-being and contains additional concerns in breast cancer $(7,8)$.

The FACT-B contains 37 questions and is structured in two sections: FACT-general (FACT-G) and a disease specific domain for breast cancer (BCS).

The FACT-G consists in four domains:

- physical wellbeing (PWB), focusing on fatigue, nausea, pain, treatment related symptoms, family care;

- social/family wellbeing (SWB): acceptance and support of family and friends;

- emotional wellbeing (EWB): feelings about the disease and its course;

- functional wellbeing (FWB): professional and personal activities, quality of sleep.

The BCS domain includes additional specific items about breast cancer: physical, psychological and aesthetical disorders due to cancer and therapies (8).

There are 7 items for PWB, 7 items for SWB, 6 items for EWB, 7 items for FWB, and 10 items for additional concerns about BCS. The values for each question range from 0 (not at all) to 4 (very much). When single questions are skipped, scores are prorated using the average of the other answers in the scale and counted in the results (9). Final scores (FACT-B-Total) of all subscales range from 0 to 148 , where 148 represents the most favorable score and accordingly a highest QoL. It is also possible to calculate a Trial Outcome Index (TOI) as the sum of the PWB, FWB and BCS as a summary index; TOI is responsive to change in physical and functional outcomes, sometimes instead of an overall multidimensional aggregated score (10).

FACT-B questionnaire was compiled by the patients themselves at the start of RT treatment (baseline assessment), at the end of RT and during follow-up visits at 3-6-18 months (maximum 5 questionnaires administered per patient). Where necessary, the patients were supported by a Physician. Estimated response time to questions was less than 10 minutes.

During the administration of the questionnaire, acute (up to 3 months after the end of RT) and late ( $>3$ months) toxicities were evaluated according to Radiation Therapy Oncology Group/European Organization for Research and Treatment of Cancer (RTOG/EORTC), respectively, at each medical control.

A comparison was made between fractionation (conventional or hypofractionation) and hormonal therapy (prescribed or not prescribed) and Age ( $<65$ years $v s . \geq 65$ years).

Preliminary analysis was made, and an upgrade of data will be conducted at 30 months after the beginning of the study.

Statistical analysis. Descriptive statistics was used to describe general and clinical characteristics of the treated patients. The distribution of data for each variable was assessed for normality
Table I. Clinical and demographic patient characteristics.

\begin{tabular}{lcccc}
\hline $\begin{array}{l}\text { Demographic } \\
\text { category }\end{array}$ & $\begin{array}{c}\text { Total } \\
95(100 \%)\end{array}$ & $\begin{array}{c}\text { DCIS } \\
13(13.7 \%)\end{array}$ & $\begin{array}{c}\text { I stage } \\
77(81.1 \%)\end{array}$ & $\begin{array}{c}\text { II stage } \\
5(5.3 \%)\end{array}$ \\
\hline $\begin{array}{l}\text { Radiation } \\
\text { schedule }\end{array}$ & & & & \\
$\begin{array}{l}\text { Conventional RT } \\
\text { Hypofractionated }\end{array}$ & $37(38.9 \%)$ & $10(76.9 \%)$ & $25(32.5 \%)$ & $2(40.4 \%)$ \\
RT & $58(61.1 \%)$ & $3(23.1 \%)$ & $52(67.5 \%)$ & $3(60.0 \%)$ \\
$\begin{array}{l}\text { Adjuvant } \\
\text { hormone }\end{array}$ & & & & \\
therapy & & & & \\
$\quad \begin{array}{l}\text { Yes } \\
\text { No }\end{array}$ & $12(12.6 \%)$ & $11(84.6 \%)$ & $1(1.3 \%)$ & $0(0.0 \%)$ \\
Age at presentation & & & & \\
$<65$ (range) & $62(65.3 \%)$ & $11(84.6 \%)$ & $49(63.6 \%)$ & $2(40.0 \%)$ \\
& $(38-64)$ & $(49-63)$ & $(40-64)$ & $(38-64)$ \\
$\geq 65$ (range) & $33(34.7 \%)$ & $2(15.4 \%)$ & $28(36.4 \%)$ & $3(60.0 \%)$ \\
& $(65-77)$ & $(70-77)$ & $(65-77)$ & $(65-70)$ \\
\hline
\end{tabular}

RT: Radiotherapy; DCIS: ductal carcinoma in situ.

using the Shapiro-Wilk test. For variables not normally distributed (tested at 95\%), non-parametric statistical tests were used, and the median was reported ( $1^{\text {st }}$ quartile $-3^{\text {rd }}$ quartile). The quality of life (QoL) was assessed by PWB, SWB, EWB, FWB, BCS, FACT-BTOI, FACT-G-Total, FACT-B-Total variables evaluated at 5 time point. An overall measure was calculated by the mean of the 5 measures. Friedman test was used to detect repeated measurement differences. The Mann-Whitney $U$-test was used to compare differences between two independent groups. Kruskal-Wallis test was used to detect differences between more than two independent groups. The Chi-squared test was used to detect independence between Age ( $<65$ years and $\geq 65$ years) and RT schedule, Hormone Therapy, Acute Skin Toxicity, Late Skin Toxicity and Late Subcutaneous Toxicity. The level for significance was set at $p<0.05$. All tests were performed using the $\mathrm{R}$ environment for statistical computing and graphics version 3.5.2 (R Foundation for Statistical Computing, Vienna, Austria; https://www.R-project.org/).

\section{Results}

From 2018 to 2020, a total of 105 early BC patients were selected and recruited in the Radiation Oncology Departments of Chieti, Italy. Among 105 patients, 95 completed at least three FACT-B questionnaires and their data were analyzed. From March 2020, due to the COVID-19 pandemic, the questionnaires were administered via telephone. Clinical and demographic patient characteristics are listed in Table I.

All patients underwent adjuvant RT after breast conservative surgery. The average age of the enrolled patients was 59.3 \pm 9.1 years (range=38-77). Seventy-seven patients $(81.1 \%)$ presented stage I disease with invasive breast cancer. Eighty-three patients $(87.4 \%)$ were hormone receptor status positive and received adjuvant HT concurrently with RT. In addition, 28 (33.8\%) of these 
Table II. Median score (1 ${ }^{\text {st }}$ Quartile - $3^{\text {rd }}$ Quartile) and range (in brackets) for all Functional Assessment of Cancer Therapy-Breast variables at the time of administration of the questionnaire.

\begin{tabular}{|c|c|c|c|c|c|c|c|}
\hline \multirow[t]{2}{*}{ Variable } & \multicolumn{5}{|c|}{ Questionnaire } & \multirow[t]{2}{*}{$p$-Value } & \multirow[t]{2}{*}{ Overall } \\
\hline & I & II & III & IV & $\mathrm{V}$ & & \\
\hline PWB & $\begin{array}{c}26 \\
(23-28)\end{array}$ & $\begin{array}{c}25 \\
(22-27)\end{array}$ & $\begin{array}{c}25 \\
(23-27)\end{array}$ & $\begin{array}{c}24 \\
(22-26)\end{array}$ & $\begin{array}{c}20 \\
(16-25)\end{array}$ & 0.290 & $\begin{array}{c}24.7 \\
(22.3-26.7)\end{array}$ \\
\hline SWB & $\begin{array}{c}22.1 \\
(17-26)\end{array}$ & $\begin{array}{c}21 \\
(17.5-25)\end{array}$ & $\begin{array}{c}20 \\
(15.2-24)\end{array}$ & $\begin{array}{c}21 \\
(17.5-25)\end{array}$ & $\begin{array}{c}21 \\
(16.3-25)\end{array}$ & 0.838 & $\begin{array}{c}20.6 \\
(17.7-24)\end{array}$ \\
\hline EWB & $\begin{array}{c}19 \\
(17-21)\end{array}$ & $\begin{array}{c}19.5 \\
(16.9-21)\end{array}$ & $\begin{array}{c}19 \\
(16-20.4)\end{array}$ & $\begin{array}{c}19 \\
(17-22)\end{array}$ & $\begin{array}{c}18 \\
(15.6-21)\end{array}$ & 0.264 & $\begin{array}{c}18.8 \\
(17-20.3)\end{array}$ \\
\hline FWB & $\begin{array}{c}17 \\
(13-22)\end{array}$ & $\begin{array}{c}17 \\
(14-20)\end{array}$ & $\begin{array}{c}16 \\
(13-21)\end{array}$ & $\begin{array}{c}19 \\
(15-21)\end{array}$ & $\begin{array}{c}17 \\
(15-24)\end{array}$ & 0.182 & $\begin{array}{c}17.3 \\
(14.3-20.1)\end{array}$ \\
\hline $\mathrm{BCS}$ & $\begin{array}{c}28 \\
(23-32)\end{array}$ & $\begin{array}{c}30 \\
(26-32)\end{array}$ & $\begin{array}{c}28.8 \\
(25-32)\end{array}$ & $\begin{array}{c}29 \\
(26.6-32)\end{array}$ & $\begin{array}{c}27 \\
(23-30)\end{array}$ & 0.467 & $\begin{array}{c}28.3 \\
(25.7-31.5)\end{array}$ \\
\hline FACT-B TOI & $\begin{array}{c}71.4 \\
(62.3-78.2)\end{array}$ & $\begin{array}{c}69 \\
(63.05-76.5)\end{array}$ & $\begin{array}{c}70 \\
(64-76)\end{array}$ & $\begin{array}{c}71 \\
(64-78)\end{array}$ & $\begin{array}{c}65 \\
(58-74)\end{array}$ & 0.302 & $\begin{array}{c}69.5 \\
(63-76)\end{array}$ \\
\hline FACT-G Total & $\begin{array}{c}82 \\
(74-93)\end{array}$ & $\begin{array}{c}80.9 \\
(72.5-89)\end{array}$ & $\begin{array}{c}78.7 \\
(72.3-86)\end{array}$ & $\begin{array}{c}81 \\
(73-90)\end{array}$ & $\begin{array}{c}80.3 \\
(66-94)\end{array}$ & 0.947 & $\begin{array}{c}82 \\
(74-88.3)\end{array}$ \\
\hline FACT-B Total & $\begin{array}{c}111.4 \\
(101.1-122.5)\end{array}$ & $\begin{array}{c}108 \\
(99-117.25)\end{array}$ & $\begin{array}{c}109 \\
(98-116)\end{array}$ & $\begin{array}{c}111 \\
(101-120)\end{array}$ & $\begin{array}{c}103.3 \\
(93-120)\end{array}$ & 0.441 & $\begin{array}{c}109.1 \\
(99.7-117.2)\end{array}$ \\
\hline
\end{tabular}

PWB: Physical wellbeing; SWB: social/family wellbeing; EWB: emotional wellbeing; FWB: functional wellbeing; BCS: breast cancer specific concerns; FACT-B-TOI: Functional Assessment of Cancer Therapy-Breast-Trial Outcome Index; FACT-G-Total: Functional Assessment of Cancer Therapy-General-Total. * License to use the module and the scoring system may be obtained on www.facit.org. Friedman test was used to detect repeated measurement differences. Overall regarded the median scores for each variable during time.

women received anti-estrogens, luteinizing hormonereleasing hormone (LHRH) agonists.

Thirty-seven patients $(38.9 \%)$ received conventional fractionated schedule $(50 \mathrm{~Gy}-2.0 \mathrm{~Gy} / \mathrm{die})$ and 58 patients $(61.1 \%)$ received hypofractionated regimen (42.5 Gy-2.6 Gy/die). Forty-three patients $(45.3 \%)$ got a sequential electron boost (10-14 Gy) to the tumor bed region.

Table II shows the median values of the variables for the QoL evaluation at any time of administration. For each variable we obtained a $p>0.05$, showing no differences for all variables in the five questionnaires. Therefore, the QoL scores did not change significantly during or after RT.

Table III shows the differences for the FACT-B variables with respect to RT schedule (conventional fractionated $v s$. hypofractionation) and HT. Statistically significant differences of EWB (emotional wellbeing, $p=0.044$ ), FWB (functional wellbeing, $p=0.009$ ), and FACT-B-Total (Functional Assessment of Cancer Therapy-General-Total, $p=0.011$ ) was observed between patients treated or not with adjuvant HT (87.4\% patients).

Acute and late toxicities were collected at each medical evaluation and detailed in Table IV. Grade 3 and 2 acute skin toxicity was reported in $4.0 \%$ (4 patients) and $52.6 \%$ (50 patients) of cases. With a median follow-up of 16 months (622) any Grade $>1$ late toxicity was observed.

Table $\mathrm{V}$ shows the median $\left(1^{\text {st }}\right.$ quartile $-3^{\text {rd }}$ quartile) for the QoL variables with respect to skin toxicity. No differences were found for any of the QoL variables with respect to Cutaneous Toxicity.

QoL overall measurements and FACT variables were examined for women aged $<65$ years and $\geq 65$ years. No significant differences for age were detected in QoL (Table VI). For RT schedule (conventional fractionated $v s$. hypofractionation) and HT the Chi-square test confirmed independence of factors (Table VII). Focusing on RT-side effects and age, elderly patients experienced more often an acute G2 toxicity (51.5\%) compared to the younger group, in which the prevalent toxicity was G1 (54.8\%).

Regarding late toxicity, no differences were found for any variables of FACT-B questionnaire. Besides, we signal a greater incidence of late G1 skin $(24.2 \%$ vs. $12.9 \%)$ and subcutaneous $(12.1 \% \mathrm{vs} .0 .0 \%)$ toxicity in patients aged $\geq 65$ years. Table VII shows frequencies (column percentages) with respect to age groups for RT schedule (conventional fractionated $v s$. hypofractionation), HT and toxicities. For Acute Skin Toxicity and Late Sub-cutaneous Toxicity, the null hypothesis of independence is rejected: there is an association between age and toxicity levels $(p<0.001$ and $p<0.013$, respectively).

\section{Discussion}

The aim of this prospective observational study was to evaluate if RT, HT, treatment-related toxicities, and age 
in vivo $35: 1821-1828(2021)$

Table III. Difference for scores and range (in brackets) of all Functional Assessment of Cancer Therapy-Breast variables for RT schedule (conventional fractionated versus hypofractionation) and HT, and p-Value for Mann U Whitney test.

\begin{tabular}{|c|c|c|c|c|c|c|}
\hline \multirow{2}{*}{$\begin{array}{l}\text { Variable } \\
\text { Overall }\end{array}$} & \multicolumn{2}{|c|}{ RT schedule } & \multirow[b]{2}{*}{$p$-Value } & \multicolumn{2}{|c|}{ Hormone therapy } & \multirow[b]{2}{*}{$p$-Value } \\
\hline & Hypofractionated & Conventional & & No & Yes & \\
\hline PWB & $\begin{array}{c}24.8 \\
(22.9-26.6)\end{array}$ & $\begin{array}{c}24.4 \\
(22-26.8)\end{array}$ & 0.748 & $\begin{array}{c}25.7 \\
(23.8-27.4)\end{array}$ & $\begin{array}{c}24.3 \\
(22-26.5)\end{array}$ & 0.061 \\
\hline SWB & $\begin{array}{c}20.9 \\
(18.8-24.5)\end{array}$ & $\begin{array}{c}20.5 \\
(17.2-23.7)\end{array}$ & 0.323 & $\begin{array}{c}22 \\
(18.2-25.5)\end{array}$ & $\begin{array}{c}20.5 \\
(17.7-23.7)\end{array}$ & 0.246 \\
\hline EWB & $\begin{array}{c}18.3 \\
(17-20.1)\end{array}$ & $\begin{array}{c}19 \\
(16.7-20.8)\end{array}$ & 0.372 & $\begin{array}{c}20 \\
(17.9-21.7)\end{array}$ & $\begin{array}{c}18.3 \\
(16.3-20.3)\end{array}$ & 0.044 \\
\hline FWB & $\begin{array}{c}17 \\
(14-20)\end{array}$ & $\begin{array}{c}17.4 \\
(14.3-20.8)\end{array}$ & 0.420 & $\begin{array}{c}20.1 \\
(16.8-23.2)\end{array}$ & $\begin{array}{c}16.8 \\
(14-19.3)\end{array}$ & 0.009 \\
\hline $\mathrm{BCS}$ & $\begin{array}{c}28.3 \\
(26.2-31.1)\end{array}$ & $\begin{array}{c}28.3 \\
(25.2-31.6)\end{array}$ & 0.805 & $\begin{array}{c}29 \\
(26.4-31)\end{array}$ & $\begin{array}{c}27.8 \\
(25.3-31.6)\end{array}$ & 0.729 \\
\hline FACT-B TOI & $\begin{array}{c}69 \\
(65.1-74.3)\end{array}$ & $\begin{array}{c}70.6 \\
(60.5-76.7)\end{array}$ & 0.820 & $\begin{array}{c}73 \\
(67.1-80.5)\end{array}$ & $\begin{array}{c}69.1 \\
(61.6-74.5)\end{array}$ & 0.064 \\
\hline FACT-G Total & $\begin{array}{c}81.2 \\
(74.9-87.7)\end{array}$ & $\begin{array}{c}82.3 \\
(73-89.7)\end{array}$ & 0.955 & $\begin{array}{c}86.1 \\
(79.5-96)\end{array}$ & $\begin{array}{c}79.3 \\
(73.2-86.5)\end{array}$ & 0.051 \\
\hline FACT-B Total & $\begin{array}{c}108.4 \\
(100.9-115)\end{array}$ & $\begin{array}{c}109.5 \\
(95-119)\end{array}$ & 0.902 & $\begin{array}{c}113.1 \\
(104.4-124.5)\end{array}$ & $\begin{array}{c}106.6 \\
(97.9-115.2)\end{array}$ & 0.011 \\
\hline
\end{tabular}

RT: Radiotherapy; PWB: physical wellbeing; SWB: social/family wellbeing; EWB: emotional wellbeing; FWB: functional wellbeing; BCS: breast cancer specific concerns; FACT-B-TOI: Functional Assessment of Cancer Therapy-Breast-Trial Outcome Index; FACT-G-Total: Functional Assessment of Cancer Therapy-General-Total. *License to use the module and the scoring system may be obtained on www.facit.org. Bold values show statistical significance.

would affect QoL of early BC patients. In our study, the overall FACT-B scores showed no changes during and after RT. This suggest that the patients who were enrolled did not experience a worsening of QoL due to RT, in line with findings in previous literature.

In a prospective study of 2016, early BC patients treated with post-lumpectomy RT showed a stable QoL during and after treatment (11). In an earlier large phase 3 randomized clinical trial, Prescott et al. compared QoL of early-stage in $\mathrm{BC}$ patients who received or did not receive adjuvant RT. Their results reported similar QoL between their two treatment arms within 15 months after surgery (12) and were corroborated in a longer follow-up (5-years), confirming the robustness of observations (13).

In another study patients treated with conservative surgery and RT with or without systemic therapy reported high and stable QoL for up to 15 years of follow-up. In addition, the patient scores were comparable to those seen in non-BC patients (14). Referring to the adopted RT schedules, international literature is controversial. Munshi et al. (15) in 2010 supported a non-significant impact of the total duration of radiation treatment on post-RT QoL scores. On the other hand, Hamer et al. in 2016 suggested that patients treated with conventional RT regimen may experience worse QoL compared to those who underwent a hypofractionated dose due to a greater number of hospital visits, with several implications on patients' life. These findings are also
Table IV. Acute and late toxicities collected during all medical evaluations according to Radiation Therapy Oncology Group/European Organization for Research and Treatment of Cancer (RTOG/EORTC), respectively.

\begin{tabular}{lcc}
\hline Acute & Grade & $\mathrm{N}(\%)$ \\
\hline Skin & 0 & $28(29.47 \%)$ \\
& 1 & $50(52.63 \%)$ \\
\multirow{2}{*}{ Lung } & 2 & $13(13.68 \%)$ \\
Heart & 3 & $4(4.21 \%)$ \\
\hline Late & 0 & $94(98.95 \%)$ \\
\hline Skin & 1 & $1(1.05 \%)$ \\
Sub-cutaneous & 0 & $95(100 \%)$ \\
\multirow{2}{*}{ Lung } & Grade & $\mathrm{N}(\%)$ \\
Heart & 0 & $79(83.16 \%)$ \\
Bone & 1 & $16(16.84 \%)$ \\
& 0 & $91(95.79 \%)$ \\
& 1 & $4(4.21 \%)$ \\
& 0 & $95(100 \%)$ \\
& 0 & $95(100 \%)$ \\
\end{tabular}

confirmed by a recent study in which QoL of BC patients was improved when a hypofractionated regimen was chosen (16). In accordance with Munshi et al., our study did not objectively detect any changes in QoL of patients treated 
Table V. Difference for scores and ranges (in brackets) of all Functional Assessment of Cancer Therapy-Breast variables for skin toxicity.

\begin{tabular}{|c|c|c|c|c|c|c|c|}
\hline \multirow{2}{*}{$\begin{array}{l}\text { Variable } \\
\text { Overall }\end{array}$} & \multicolumn{3}{|c|}{ Acute skin toxicity } & \multicolumn{2}{|c|}{ Late skin toxicity } & \multicolumn{2}{|c|}{ Late sub-cutaneous toxicity } \\
\hline & G0 & G1 & $\mathrm{G} 2$ & G0 & G1 & G0 & G1 \\
\hline PWB & $\begin{array}{c}24.1 \\
(22.1-25.5)\end{array}$ & $\begin{array}{c}24.4 \\
(22-26.3)\end{array}$ & $\begin{array}{c}26.6 \\
(24.7-27.5)\end{array}$ & $\begin{array}{c}24.5 \\
(22-26.6)\end{array}$ & $\begin{array}{c}25.5 \\
(23.2-27.4)\end{array}$ & $\begin{array}{c}24.7 \\
(22-26.8)\end{array}$ & $\begin{array}{c}24.1 \\
(22.8-25.5)\end{array}$ \\
\hline SWB & $\begin{array}{c}22.1 \\
(19.2-25.8)\end{array}$ & $\begin{array}{c}20.4 \\
(17.1-23)\end{array}$ & $\begin{array}{c}20.3 \\
(17.2-24.4)\end{array}$ & $\begin{array}{c}20.6 \\
(17.3-24.4)\end{array}$ & $\begin{array}{c}20.8 \\
(18.9-23.3)\end{array}$ & $\begin{array}{c}20.6 \\
(17.7-24)\end{array}$ & $\begin{array}{c}22 \\
(17.3-25.6)\end{array}$ \\
\hline EWB & $\begin{array}{c}18.4 \\
(16.6-20.5)\end{array}$ & $\begin{array}{c}19 \\
(17-20.3)\end{array}$ & $\begin{array}{c}17.8 \\
(17.3-20.3)\end{array}$ & $\begin{array}{c}18.5 \\
(16.7-20.3)\end{array}$ & $\begin{array}{c}19.6 \\
(17.9-20.5)\end{array}$ & $\begin{array}{c}18.6 \\
(17-20.3)\end{array}$ & $\begin{array}{c}19.9 \\
(18.9-20.4)\end{array}$ \\
\hline FWB & $\begin{array}{c}18.2 \\
(14.6-22)\end{array}$ & $\begin{array}{c}17 \\
(13.8-19)\end{array}$ & $\begin{array}{c}18 \\
(14-20)\end{array}$ & $\begin{array}{c}17.4 \\
(14.3-20.8)\end{array}$ & $\begin{array}{c}16.9 \\
(13.7-19)\end{array}$ & $\begin{array}{c}17.3 \\
(14-20.5)\end{array}$ & $\begin{array}{c}16.9 \\
(15.7-18)\end{array}$ \\
\hline $\mathrm{BCS}$ & $\begin{array}{c}27.5 \\
(25.1-30.6)\end{array}$ & $\begin{array}{c}28.9 \\
(25.8-31.5)\end{array}$ & $\begin{array}{c}28.3 \\
(26.4-31.8)\end{array}$ & $\begin{array}{c}27.5 \\
(25.2-31.1)\end{array}$ & $\begin{array}{c}30.3 \\
(27.3-32.2)\end{array}$ & $\begin{array}{c}28.3 \\
(25.7-31.2)\end{array}$ & $\begin{array}{c}29.9 \\
(27.3-31.9)\end{array}$ \\
\hline FACT-B TOI & $\begin{array}{c}69.9 \\
(65.5-75.8)\end{array}$ & $\begin{array}{c}68.4 \\
(62-74.8)\end{array}$ & $\begin{array}{c}73.3 \\
(65.4-79.3)\end{array}$ & $\begin{array}{c}69 \\
(62-76.7)\end{array}$ & $\begin{array}{c}72.1 \\
(68.3-74.6)\end{array}$ & $\begin{array}{c}69.2 \\
(62.8-76.4)\end{array}$ & $\begin{array}{c}71.6 \\
(67.6-73)\end{array}$ \\
\hline FACT-G Total & $\begin{array}{c}82.8 \\
(75.9-93.8)\end{array}$ & $\begin{array}{c}78.5 \\
(72.2-87.1)\end{array}$ & $\begin{array}{c}82.3 \\
(77.2-91.8)\end{array}$ & $\begin{array}{c}80.4 \\
(73.7-88.4)\end{array}$ & $\begin{array}{c}83 \\
(76.4-88.1)\end{array}$ & $\begin{array}{c}82 \\
(74-88.3)\end{array}$ & $\begin{array}{c}83.5 \\
(76.1-89.9)\end{array}$ \\
\hline FACT-B Total & $\begin{array}{c}110.7 \\
(101.2-121.1)\end{array}$ & $\begin{array}{c}104.9 \\
(97.9-116.4)\end{array}$ & $\begin{array}{c}110.8 \\
(106.8-117.2)\end{array}$ & $\begin{array}{c}107 \\
(98.1-116.4)\end{array}$ & $\begin{array}{c}111 \\
(107.6-118.9)\end{array}$ & $\begin{array}{c}109 \\
(99.2-117.2)\end{array}$ & $\begin{array}{c}113.6 \\
(105.1-118.5)\end{array}$ \\
\hline
\end{tabular}

PWB: Physical wellbeing; SWB: social/family wellbeing; EWB: emotional wellbeing; FWB: functional wellbeing; BCS: breast cancer specific concerns; FACT-B-TOI: Functional Assessment of Cancer Therapy-Breast-Trial Outcome Index; FACT-G-Total: Functional Assessment of Cancer Therapy-General-Total. *License to use the module and the scoring system may be obtained on www.facit.org.

with conventional fractionation, reporting similar scores in all subscales when compared to patients undergoing hypofractionated regimen (15).

Moreover, BC is approached with a multimodal treatment strategy, including HT, that may impact patient QoL in different ways. Common treatment side-effects are fatigue, hot flashes, pain, sexual dysfunction, arthralgia, neuropathy, cognitive dysfunction, lymphedema, cardiac morbidity (17). Some symptoms may have a multiple negative impact on QoL, causing asthenia and hampering sleep. These morbidities are investigated in FACT-B questionnaire through specific BC related items. It is not easy to attribute $\mathrm{QoL}$ effects, such as BC-related symptoms, to a specific adjuvant strategy in a multimodal therapy. In this scenario, Fallowfield et al. assumed that for some young women with a good prognosis, induction of a premature menopause may be considered too high a price to pay for adjuvant therapy (17).

Some studies focusing on adjuvant HT in early-stage BC have reported similar impact of anastrozole and tamoxifene on QoL in postmenopausal patients, and the maintenance of their side-effects during all treatments (18). Most of our patients were hormone receptor-positive and received adjuvant HT (87.4\%); 28 (33.8\%) of these women took antiestrogens, luteinizing hormone-releasing hormone (LHRH) agonists. Our analysis showed a worsening of emotional wellbeing (EWB) $(p=0.044)$, functional wellbeing $(\mathrm{FWB})$ $(p=0.009)$, and FACT-B-Total $(p=0.011)$ in the HT group.

Concerning RT toxicity, it is known that acute and late effects on normal tissues could adversely contribute to body
Table VI. Median (1 ${ }^{\text {st }}$ Quartile - $3^{\text {rd }}$ Quartile) scores and range (in brackets) for all Functional Assessment of Cancer Therapy-Breast variables by Age group.

\begin{tabular}{lccc}
\hline Variable & \multicolumn{2}{c}{ Age } & \multirow{2}{*}{$p$-Value } \\
\cline { 2 - 3 } & \multicolumn{2}{c}{$<$ years } & $\geq 65$ years \\
\hline PWB & $24.5(22.4-26.3)$ & $25.0(22.0-26.8)$ & 0.511 \\
SWB & $21.3(18.8-24.5)$ & $19.5(17.1-22.5)$ & 0.161 \\
EWB & $19.0(17.0-20.5)$ & $17.9(17.0-20.3)$ & 0.217 \\
FWB & $17.9(15.1-20.8)$ & $16.3(13.8-19.0)$ & 0.072 \\
BCS & $28.7(25.7-31.2)$ & $28.3(25.8-31.5)$ & 0.716 \\
FACT-B-TOI & $69.4(63.3-76.0)$ & $69.7(62.0-75.3)$ & 0.477 \\
FACT-G-Total & $82.8(74.9-89.7)$ & $78.9(73.0-83.4)$ & 0.430 \\
FACT-B-Total & $109.4(99.7-119.2)$ & $109.0(99.7-112.6)$ & 0.111 \\
\hline
\end{tabular}

PWB: Physical wellbeing; SWB: social/family wellbeing; EWB: emotional wellbeing; FWB: functional wellbeing; BCS: breast cancer specific concerns; FACT-B-TOI: Functional Assessment of Cancer Therapy-Breast-Trial Outcome Index; FACT-G-Total: Functional Assessment of Cancer Therapy-General-Total. Bold values show significance. $p$-Values result from Mann $U$ Whitney test. *License to use the module and the scoring system may be obtained on www.facit.org.

image and related QoL parameters (19). Skin RT-related toxicity negatively affects QoL of BC patients in multipledimension analysis (20). In this respect, a study conducted in 2016 from Hannah et al. investigating QoL among early BC patients, found higher FACT-B scores in patients with Grade 0-1 CTCAE toxicities versus Grade 2-3 (21). 
Table VII. Frequency (Column percentage) with respect to Age for RT schedule (conventional fractionated vs. hypofractionation), HT and toxicities.

\begin{tabular}{|c|c|c|c|}
\hline \multirow[t]{2}{*}{ Variable } & \multicolumn{2}{|c|}{ AGE } & \multirow[t]{2}{*}{$p$-Value } \\
\hline & $<65$ years & $\geq 65$ years & \\
\hline \multicolumn{4}{|l|}{ RT schedule } \\
\hline Hypofractionated & $32(51.6 \%)$ & $12(36.4 \%)$ & \multirow[t]{2}{*}{0.229} \\
\hline Conventional & $30(48.4 \%)$ & $21(63.6 \%)$ & \\
\hline \multicolumn{4}{|l|}{ Hormone therapy } \\
\hline No & $20(32.3 \%)$ & $4(12.1 \%)$ & \multirow[t]{2}{*}{0.057} \\
\hline Yes & $42(67.7 \%)$ & $29(87.9 \%)$ & \\
\hline \multicolumn{4}{|l|}{ Acute skin toxicity } \\
\hline G0 & $28(45.2 \%)$ & $0(0.0 \%)$ & \multirow[t]{3}{*}{$<0.001$} \\
\hline G1 & $34(54.8 \%)$ & $16(48.5 \%)$ & \\
\hline $\mathrm{G} 2$ & $0(0.0 \%)$ & $17(51.5 \%)$ & \\
\hline \multicolumn{4}{|l|}{ Late skin toxicity } \\
\hline G0 & $54(87.1 \%)$ & $25(75.8 \%)$ & \multirow[t]{2}{*}{0.162} \\
\hline G1 & $8(12.9 \%)$ & $8(24.2 \%)$ & \\
\hline \multicolumn{4}{|l|}{$\begin{array}{l}\text { Late sub-cutaneous } \\
\text { toxicity }\end{array}$} \\
\hline G0 & $62(100.0 \%)$ & $29(87.9 \%)$ & \multirow[t]{2}{*}{0.013} \\
\hline G1 & $0(0.0 \%)$ & $4(12.1 \%)$ & \\
\hline
\end{tabular}

RT: Radiotherapy. Bold values show statistical significance.

The patients treated in our Center received weekly medical visits during RT and at 3-6-18 months during follow-up. Good tolerance profile was reported in terms of both acute and late toxicities, showing no significative implications on QoL.

In terms of implications related to age, younger patients are more likely to suffer adverse effects because of early menopause induction and potential infertility. This patient group is more likely to have a lower QoL $(22,23)$ and to be more vulnerable to the emotional burden and psychological impact of BC. Furthermore, in other studies older patients appear more vulnerable to a reduced QoL, in accordance with reduced physical functioning after surgery and adjuvant therapy $(23,24)$. In a 2009 review on long-term BC survivors, older patients seemed better prepared mentally to deal with treatments, despite their age-related co-morbidities $(25,26)$ as opposed to younger patients.

Khool et al. found that BC patients preferred avoiding severe breast symptoms rather than obtaining a longer 2-year disease-free survival. While younger patients assign higher importance to a 2-year longer disease-free survival, older patients are more afraid of receiving systemic therapies (27).

Although a significant worst G1 toxicity was assessed in older patients regarding acute skin toxicity $(p<0.001)$ and late sub-cutaneous toxicity ( $p=0.013$ ), our data did not show difference in QoL between two age groups $(<65$ years $v s$. $\geq 65$ years) concerning RT fractionation $(p=0.229)$ or HT $(p=0.057)$. These results are in line with those of Kunkler et al. which assumed that postoperative RT after breast conserving surgery did not seem to compromise older patients' QoL (28).

In conclusion, our cohort was represented by a rather homogeneous group of patients in a favorable stage. The FACT-B questionnaire was confirmed as a quick and easy way to assess QoL in early-BC patients. The long survival rates and increasing proportions of cured patients require dedicated strategies to manage long-term sequelae of $\mathrm{BC}$ treatments, with particular attention to QoL (28). Currently the definition of QoL is not universally accepted; it changed over the years, becoming more complex and enriched across several disciplines. It should be viewed as multidimensional $(29,30)$, emphasizing the self-perception of the individual's current state of mind $(31,32)$. The results of our study reflect the actual situation and seem to be promising with positive patient satisfaction with the treatment.

On the other hand, nowadays breast cancer survivorship is one of the most challenging aspects to be investigated in dedicated clinical trials with a larger number of patients and a longer follow-up. Furthermore, the study is still ongoing to validate our results on QoL reaching a median follow-up of 30 months. The analysis will be conducted to assess an eventual "rebound effect" on QoL, as described in a study conducted by Holzner et al. (33). This type of study, focusing on patients' QoL with long-term follow-up may help monitor the outcomes considered most important by patients, with a consequent greater satisfaction of care provided (33).

\section{Conflicts of Interest}

The Authors report no conflicts of interest.

\section{Authors' Contributions}

LAU, MN, DG and LC designed and coordinated the study and analysis. FCDG, MB, AA, FP and CDC provided data. FCDG, CR and MDT performed main data analysis and provided pictures elaboration. AP and MDN performed statistical data analysis. LAU, MN, CR, FCDG, MB, MDT and MT drafted the manuscript. DG and LC critically revised the study and the manuscript. All Authors reviewed and approved the final manuscript.

\section{References}

1 Van Dijck S, Nelissen P, Verbelen H, Tjalma W and Gebruers N: The effects of physical self-management on quality of life in breast cancer patients: A systematic review. Breast 28: 20-28, 2016. PMID: 27173849. DOI: 10.1016/j.breast.2016.04.010

2 Chopra I and Kamal K: A systematic review of quality of life instruments in long-term breast cancer survivors. Health and Quality of Life Outcomes 10(1): 14, 2016. DOI: 10.1186/14777525-10-14

3 Montazeri A: Health-related quality of life in breast cancer patients: A bibliographic review of the literature from 1974 to 
2007. J Exp Clin Cancer Res 27: 32, 2008. PMID: 18759983 DOI: $10.1186 / 1756-9966-27-32$

4 Lemieux J, Goodwin PJ, Bordeleau LJ, Lauzier S and Théberge $\mathrm{V}$ : Quality-of-life measurement in randomized clinical trials in breast cancer: An updated systematic review (2001-2009). J Natl Cancer Inst 103(3): 178-231, 2011. PMID: 21217081. DOI: $10.1093 /$ jnci/djq508

5 Hamer J, McDonald R, Zhang L, Verma S, Leahey A, Ecclestone C, Bedard G, Pulenzas N, Bhatia A, Chow R, DeAngelis C, Ellis J, Rakovitch E, Lee J and Chow E: Quality of life (QOL) and symptom burden (SB) in patients with breast cancer. Support Care Cancer 25(2): 409-419, 2017. PMID: 27696078. DOI: 10.1007/s00520-016-3417-6

6 Brady MJ, Cella DF, Mo F, Bonomi AE, Tulsky DS, Lloyd SR, Deasy S, Cobleigh M and Shiomoto G: Reliability and validity of the functional assessment of cancer therapy-breast quality-oflife instrument. J Clin Oncol 15(3): 974-986, 1997. PMID: 9060536. DOI: 10.1200/JCO.1997.15.3.974

7 Cella DF, Tulsky DS, Gray G, Sarafian B, Linn E, Bonomi A, Silberman M, Yellen SB, Winicour $\mathrm{P}$ and Brannon $\mathrm{J}$ : the functional assessment of cancer therapy scale: Development and validation of the general measure. J Clin Oncol 11(3): 570-579, 1993. PMID: 8445433. DOI: 10.1200/JCO.1993.11.3.570

8 Di Bella O, Cocchiara RA, De Luca A, Frusone F, Aceti V, Sestili C, D'Egidio V, Mannocci A, Monti M and La Torre G: Functional assessment of cancer therapy questionnaire for breast cancer (FACT-B+4): Italian version validation. Clin Ter 169(4): e151-e154, 2018. PMID: 30151547. DOI: 10.7417/T.2018.2071

9 Pandey M, Thomas BC, Ramdas K, Eremenco S and Nair MK: Quality of life in breast cancer patients: Validation of a FACTB Malayalam version. Qual Life Res 11(2): 87-90, 2002. PMID: 12018741. DOI: 10.1023/a:1015083713014

10 Webster K, Cella D and Yost K: The functional assessment of chronic illness therapy (FACIT) measurement system: Properties, applications, and interpretation. Health Qual Life Outcomes 1: 79, 2003. PMID: 14678568. DOI: 10.1186/14777525-1-79

11 Xiao C, Miller AH, Felger J, Mister D, Liu T and Torres MA: A prospective study of quality of life in breast cancer patients undergoing radiation therapy. Adv Radiat Oncol 1(1): 10-16, 2016. PMID: 27453954. DOI: 10.1016/j.adro.2016.01.003

12 Prescott RJ, Kunkler IH, Williams LJ, King CC, Jack W, van der Pol M, Goh TT, Lindley R and Cairns J: A randomised controlled trial of postoperative radiotherapy following breastconserving surgery in a minimum-risk older population. The PRIME trial. Health Technol Assess 11(31): 1-149, iii-iv, 2007. PMID: 17669280. DOI: 10.3310/hta11310

13 Williams LJ, Kunkler IH, King CC, Jack W and van der Pol M: A randomised controlled trial of post-operative radiotherapy following breast-conserving surgery in a minimum-risk population. Quality of life at 5 years in the PRIME trial. Health Technol Assess 15(12): i-xi, 1-57, 2011. PMID: 21366974. DOI: $10.3310 /$ hta 15120

14 Freedman GM, Li T, Anderson PR, Nicolaou N and Konski A: Health states of women after conservative surgery and radiation for breast cancer. Breast Cancer Res Treat 121(2): 519-526, 2010. PMID: 19768651. DOI: 10.1007/s10549-009-0552-5

15 Munshi A, Dutta D, Kakkar S, Budrukkar A, Jalali R, Sarin R, Gupta S, Parmar V and Badwe R: Comparison of early quality of life in patients treated with radiotherapy following mastectomy or breast conservation therapy: A prospective study. Radiother Oncol 97(2): 288-293, 2010. PMID: 20627431. DOI: 10.1016/j.radonc.2010.04.008

16 Arsenault J, Parpia S, Goldberg M, Rakovitch E, Reiter H, Doherty M, Lukka H, Sussman J, Wright J, Julian J and Whelan T: Acute toxicity and quality of life of hypofractionated radiation therapy for breast cancer. Int J Radiat Oncol Biol Phys 107(5): 943-948, 2020. PMID: 32334033. DOI: 10.1016/j.ijrobp. 2020.03.049

17 Fallowfield LJ, Leaity SK, Howell A, Benson S and Cella D: Assessment of quality of life in women undergoing hormonal therapy for breast cancer: Validation of an endocrine symptom subscale for the FACT-B. Breast Cancer Res Treat 55(2): 189199, 1999. PMID: 10481946. DOI: 10.1023/a:1006263818115

18 Reimer T and Gerber B: Quality-of-life considerations in the treatment of early-stage breast cancer in the elderly. Drugs Aging 27(10): 791-800, 2010. PMID: 20883059. DOI: 10.2165/ 11584700-000000000-00000

19 Hopwood P, Haviland J, Mills J, Sumo G, M Bliss J and START Trial Management Group: The impact of age and clinical factors on quality of life in early breast cancer: An analysis of 2208 women recruited to the UK START trial (Standardisation of Breast Radiotherapy Trial). Breast 16(3): 241-251, 2007. PMID: 17236771. DOI: 10.1016/j.breast.2006.11.003

20 Schnur JB, Ouellette SC, Dilorenzo TA, Green S and Montgomery GH: A qualitative analysis of acute skin toxicity among breast cancer radiotherapy patients. Psychooncology 20(3): 260-268, 2011. PMID: 20238306. DOI: 10.1002/ pon.1734

21 Hahn E, Segawa E, Kaiser K, Cella D and Smith B: Healthrelated quality of life among women with ductal carcinomain situor early invasive breast cancer: Validation of the FACT-B (version 4). Expert Review of Quality of Life in Cancer Care 1(1): 99-109, 2020. DOI: 10.1080/23809000.2016.1134259

22 Cohen L, Hamer J, Helwig C, Fergus K, Kiss A, Mandel R, Dawson B, Landsberg A, Shein K, Kay N and Warner E: Formal evaluation of PYNK: Breast cancer program for young womenthe patient perspective. Curr Oncol 23(2): e102-e108, 2016. PMID: 27122977. DOI: 10.3747/co.23.2773

23 Avis NE, Crawford S and Manuel J: Quality of life among younger women with breast cancer. J Clin Oncol 23(15): 33223330, 2005. PMID: 15908646. DOI: 10.1200/JCO.2005.05.130

24 Leach CR, Bellizzi KM, Hurria A and Reeve BB: Is it my cancer or am I just getting older?: Impact of cancer on age-related health conditions of older cancer survivors. Cancer 122(12): 1946-1953, 2016. PMID: 27159822. DOI: 10.1002/cncr.29914

25 Ballinger RS and Fallowfield LJ: Quality of life and patientreported outcomes in the older breast cancer patient. Clin Oncol (R Coll Radiol) 21(2): 140-155, 2009. PMID: 19056252. DOI: 10.1016/j.clon.2008.11.003

26 Mokhatri-Hesari P and Montazeri A: Health-related quality of life in breast cancer patients: Review of reviews from 2008 to 2018. Health Qual Life Outcomes 18(1): 338, 2020. PMID: 33046106. DOI: 10.1186/s12955-020-01591-x

27 Kool M, van der Sijp JR, Kroep JR, Liefers GJ, Jannink I, Guicherit OR, Vree R, Bastiaannet E, van de Velde CJ and Marang-van de Mheen PJ: Importance of patient reported outcome measures versus clinical outcomes for breast cancer patients evaluation on quality of care. Breast 27: 62-68, 2016. PMID: 27026219. DOI: 10.1016/j.breast.2016.02.015 
28 Kunkler IH, Williams LJ, King CC and Jack W: Breast radiotherapy: Considerations in older patients. Clin Oncol ( $\mathrm{R}$ Coll Radiol) 21(2): 111-117, 2009. PMID: 19121926. DOI: 10.1016/j.clon.2008.11.012

29 Nardin S, Mora E, Varughese FM, D’Avanzo F, Vachanaram AR, Rossi V, Saggia C, Rubinelli S and Gennari A: Breast cancer survivorship, quality of life, and late toxicities. Front Oncol 10: 864, 2020. PMID: 32612947. DOI: 10.3389/fonc.2020.00864

30 Porreca A, Cruz Rambaud S, Scozzari F and Di Nicola M: A fuzzy approach for analysing equitable and sustainable wellbeing in Italian regions. Int J Public Health 64(6): 935-942, 2019. PMID: 31134318. DOI: 10.1007/s00038-019-01262-9

31 Triberti S, Savioni L, Sebri V and Pravettoni G: eHealth for improving quality of life in breast cancer patients: A systematic review. Cancer Treat Rev 74: 1-14, 2019. PMID: 30658289. DOI: $10.1016 /$ j.ctrv.2019.01.003
32 Davey S, Roche A, Pegba-Otemolu I, Ibrahim A and Ainsworth R: Comparison of patient satisfaction on a day-case mastectomy pathway for breast cancer versus a traditional inpatient delivery model, using a validated questionnaire. Anticancer Res 40(4): 21792183, 2020. PMID: 32234912. DOI: 10.21873/anticanres.14178

33 Holzner B, Kemmler G, Kopp M, Moschen R, Schweigkofler H, Dünser M, Margreiter R, Fleischhacker WW and SpernerUnterweger B: Quality of life in breast cancer patients-not enough attention for long-term survivors? Psychosomatics 42(2): 117-123, 2001. PMID: 11239124. DOI: 10.1176/appi.psy. 42.2.117

Received February 15, 2021

Revised March 1, 2021

Accepted March 9, 2021 